\title{
SYNTHESIS AND CHARACTERIZATION OF ZNO MICROCRYSTAL TUBES
}

\author{
CHANGQUAN LI', YUAN LI' LAITAO LUO ${ }^{2 *}$ AND MINGONG FU \\ ${ }^{1}$ School of Material Science and Engineering \\ ${ }^{2}$ Department of Chemistry, \\ Nanchang University, \\ Nanchang 330031, China \\ (Accepted: January 11, 2008) - Accepted: June 11, 2008)
}

\begin{abstract}
Zinc oxide microcrystal tubes were prepared by using $\mathrm{H}_{2} \mathrm{O}_{2}$-activated $\mathrm{Zn}$ powder and active carbon as raw materials. The prepared samples were characterized by powder X-ray diffraction, scanning electron microscopy and fluorescence spectrophotometer. The results indicate that $\mathrm{ZnO}$ microcrystal has tubular structure with large slenderness ratio, and hexagonal cross sections for both intine and ectotheca. When excitated at 380 nm, two photoluminescence bands of ZnO microcrystal tubes appear, one is a strong emission at $383 \mathrm{~nm}$ (near UV band-edge) and the other a broad green emission band centered at $500 \mathrm{~nm}$. The intensity of green emission peak is far weaker than that of near UV band-edge emission peak, which suggests low defect density and fine quality of the product.
\end{abstract}

Keywords: Zinc oxide; Microcrystal tubes; Photoluminescence spectrum

\section{INTRODUCTION}

Since the discovery of carbon nanotubes by Iijima in $1991^{1}$, the tubular materials have attracted considerable attention for their regular morphology, hollow structure and relative large surface area. Preparation and research of such tubular materials have become a hotspot ${ }^{2-6}$.

Zinc oxide is an semiconductor with band gap $3.37 \mathrm{eV}$ at room temperature. It possesses favorable optical and electrical properties, high chemical stability and melting point, which has been found useful in many photoelectric devices, such as light scattering apparatus, photodetectors, electroluminescence apparatus, nonlinear optical instruments, solar cells, transparent conducting layers, bulk acoustic wave devices and surface acoustic wave devices ${ }^{7,8}$. Consequently, preparation of $\mathrm{ZnO}$ materials with high quality is of great significance for their important applications in information and military fields.

Several methods have been reported for the synthesis of $\mathrm{ZnO}$ tube including hydrothermal method, template method and chemical vapor deposition method etc ${ }^{9-16}$. The template methods consist of surfactant soft template method and carbon nanotube (or $\mathrm{Al}_{2} \mathrm{O}_{3}$ nanotube) hard template method. However, the techniques of template methods are complicated and separation of products from templates is difficult. Moreover the products strongly depend on template. These go against preparing nanotubes with high purity. As for the chemical vapor deposition method (CVD), it needs high temperature, complicated technics and high requirement for experimental equipments, and is always used to prepare materials with themselves flake structure. Herein, we report the novel preparation method of $\mathrm{ZnO}$ tubes, which has not reported as far as we know, starting with $\mathrm{H}_{2} \mathrm{O}_{2}$-activated $\mathrm{Zn}$ powders and granular active carbon as raw materials. And this method has advantages such as cheap, facile materials and simple.

\section{EXPERIMENTAL}

1. Preparation of $\mathrm{ZnO}$ microcrystal tubes

$100 \mathrm{~g} \mathrm{Zn}$ powder were mixed with $1500 \mathrm{ml}$ deionized water and $150 \mathrm{ml}$ $\mathrm{H}_{2} \mathrm{O}_{2}$. The mixture were treated at $40-50^{\circ}$ for $3 \mathrm{~h}$ under stirring and then placed stably for $12 \mathrm{~h}$. Afterwards the obtained suspension was filtered and the solid was dried at $80^{\circ}$. Then the formed activated $\mathrm{Zn}$ powder mixed homogeneously with granular active carbon (weight ratios of activated $\mathrm{Zn}$ powder to active carbon were 2:1,1:1 and1:2, respectively) and the mixture were placed in a crucible and calcined at $950^{\circ}$ for $20 \mathrm{~min}$ in furnace. Afterwards the product was under furnace cooling.

2. Characterization of $\mathrm{ZnO}$ microcrystal tubes

$\mathrm{X}$-ray diffraction (XRD) measurements were carried out with Britain Bede $\mathrm{D} 1$ Advance diffractometer equipped with a rotating anode, $\mathrm{Cu} \mathrm{K} \alpha$ radiation. Operating voltage was $40 \mathrm{kV}$ and current $40 \mathrm{~mA}$, with a scanning rate of $0.03^{\circ} \cdot \mathrm{s}^{-1}$ from $2 \theta=20^{\circ}$ to $75^{\circ}$.

The microstructure of the samples was observed by means of a Hitachi S-570 scanning electron microscopy (SEM).

Photoluminescence and excitation spectra were performed at room temperature using a Hitachi F-4500 fluorescence spectrophotometer and a Xe lamp used as origin of excitation.

\section{RESULTS AND DISCUSSION}

1. Effect of weight ratio of $\mathrm{Zn}$ powders to active carbon on $\mathrm{ZnO}$ microcrystal tubes
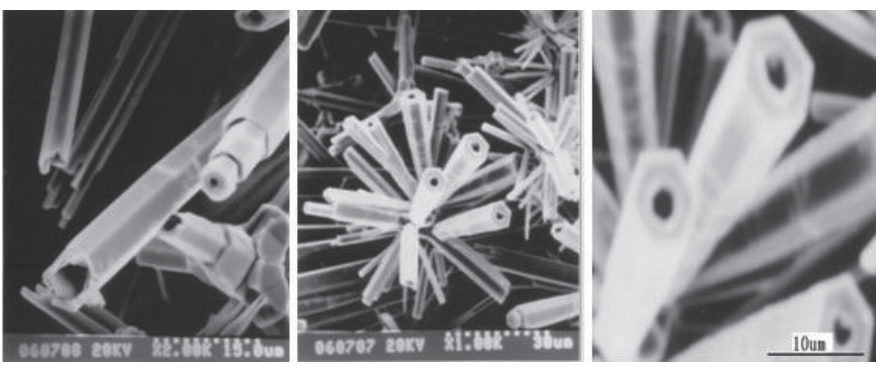

Fig.1 SEM photographs of the sample

When weight ratio of $\mathrm{Zn}$ powders to active carbon is $2: 1$, there is an amount of white accumulation in crucible, and the prepared $\mathrm{ZnO}$ possess the structure of microcrystal tubes (Fig. 1). A little white accumulation can also be seen in crucible when the weight ratio is $1: 1$. However, at weight ratio $1: 2$, hardly any white accumulation of $\mathrm{ZnO}$ is formed. The results show that the weight ratio of $\mathrm{Zn}$ powders to active carbon has great effect on $\mathrm{ZnO}$ microcrystal tube. At weight ratio $2: 1, \mathrm{ZnO}$ microcrystal tube could be obtained, and with the ratio decreasing, microcrystal tube of $\mathrm{ZnO}$ could not be formed. It is expected that with the decrease of weight ratio of $\mathrm{Zn}$ powders to active carbon, the amount of carbon increased relatively and more $\mathrm{CO}_{2}$ was formed during burning, which resulted in lower oxygen partial pressure, and thus $\mathrm{Zn}$ powders could not be well oxidized to $\mathrm{ZnO}$.

2. Characterization of $\mathrm{Zn}$ microcrystal tubes

The XRD pattern of the samples is shown in Fig. 2. The peaks at $31.7^{\circ}$, $34.4^{\circ}, 36.2^{\circ}, 47.5^{\circ}, 56.6^{\circ}, 62.8^{\circ}, 67.9^{\circ}, 69.1^{\circ}$ and $89.6^{\circ}$ represente diffraction peaks of (100), (002), (101), (102), (110), (103), (200), (112) and (201) planes of hexagonal $\mathrm{ZnO}$, respectively, and no diffraction peaks of $\mathrm{Zn}$ and other impurities are discovered. The result shows that the obtained white accumulation in crucible is microcrystal of $\mathrm{ZnO}$ with a hexagonal structure. 


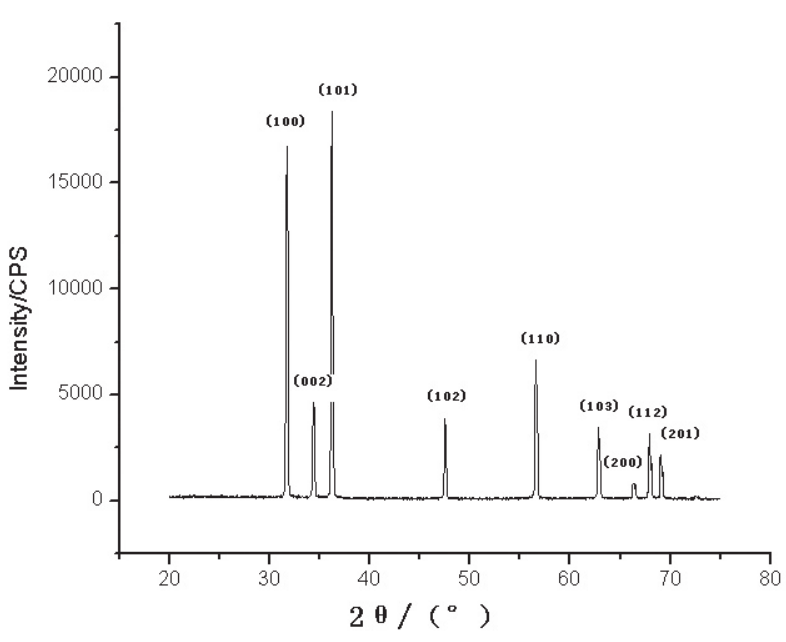

Fig.2 XRD pattern of the sample

SEM photographs of the product are shown in Fig. 1. The result reveals that the white accumulations of $\mathrm{ZnO}$ present tubular structure and slenderness ratio is relatively large. Both intine and ectotheca of tube exhibit hexagonal cross sections. Inner and external diameters of the $\mathrm{ZnO}$ microcrystal tubes are $2,6 \mu \mathrm{m}$, respectively.

As can be seen in Fig.1a, $\mathrm{ZnO}$ microcrystal tube is formed in four orientations. As gaseous $\mathrm{Zn}$ reacts with air at high temperature, $\mathrm{ZnO}$ is deposited in the crucible and crystallized in four directions. With the increase of reaction temperature, the crystal particles gradually expand, crack and are extruded by surrounding particles, then hollow structure is formed and finally reach equilibriums ${ }^{13}$. As the reaction goes on, they finally grow into regular hexagonal tubes. As known from symmetry law, in nature only triangle, quadrilateral and hexagon can overspread plane and hexagon is the steadiest. Thus $\mathrm{ZnO}$ crystal nucleuses form steady hexagon structure in the state of equilibrium.

3. Excitation and Photoluminescence Spectra

Excitation spectrum of the product at room temperature is presented in Fig. 3. As shown in Fig. 3, when monitoring wavelength is $630 \mathrm{~nm}$, there are intrinsic interband excitations of $\mathrm{ZnO}$ crystal located below $370 \mathrm{~nm}(3.35 \mathrm{ev})$, which is not obvious. In addition, there is exciton emission located below conduction

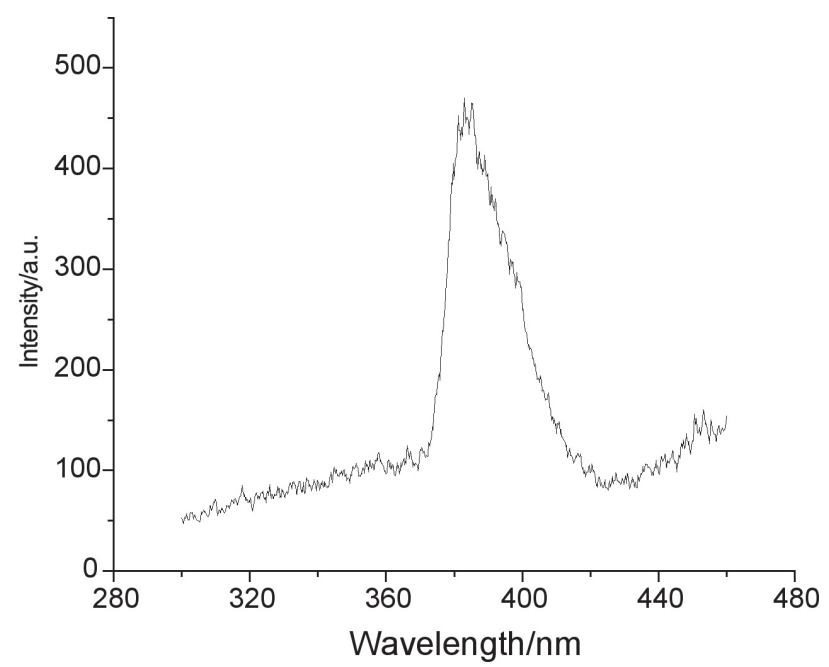

Fig.3 Excitation spectrum of the sample

band (just at $380 \mathrm{~nm}$ ) at room temperature and the width of half peak is relatively narrow.

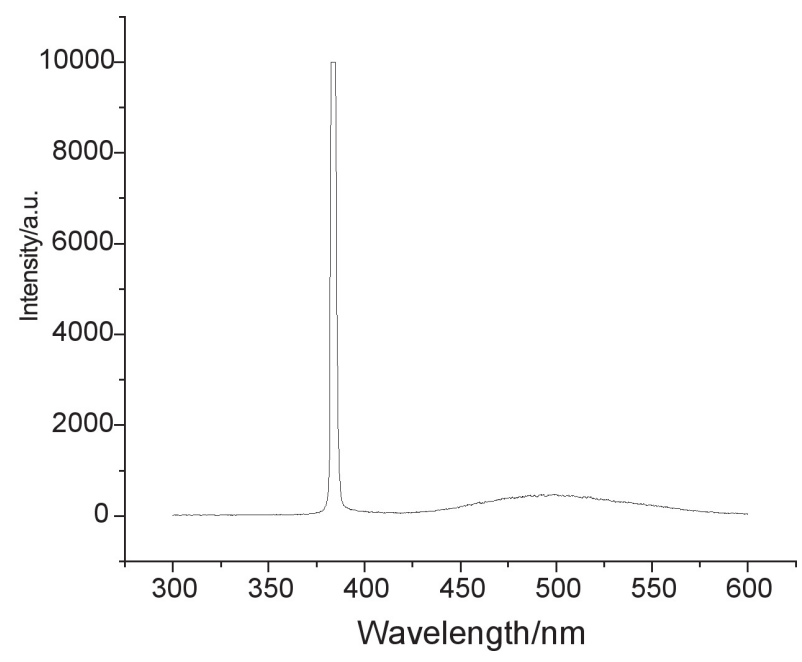

Fig.4 PL spectrum of the sample

Fig. 4 is photoluminescence spectrum of the product at room temperature. It can be seen, when the excitation wavelength is $380 \mathrm{~nm}$, there are two photoluminescence peaks: a peak of near UV band-edge emission at $383 \mathrm{~nm}$ and a green emission peak at $500 \mathrm{~nm}$. The UV emission can be attributed to the emission of free excitons. And the green emission is the deep energy level emission, which is mainly ascribed to the single oxygen ion vacancy in $\mathrm{ZnO}$. When the holes arised from a photo- excitation recombine with the electrons inhabited oxygen ions vacancy, the energy is released as the form of ray radiation ${ }^{17}$. Herein $\mathrm{ZnO}$ crystals are prepared at low partial pressure of oxygen and some oxygen ions vacancies are probably produced. Thus these oxygen ions vacancies result in the green emission of the sample. But the intensity of green emission peak is far weaker than that of near UV band-edge emission peak, implying the defect density of $\mathrm{ZnO}$ crystal is low and the product's quality is fine.

\section{CONCLUSION}

Herein we have reported a novel preparation method of $\mathrm{ZnO}$ microcrystal tubes. $\mathrm{Zn}$ powders activated by $\mathrm{H}_{2} \mathrm{O}_{2}$ and granular active carbon are used as raw materials and the obtained products exhibit tubular structure. Both intine and ectotheca of tubes show hexagonal cross sections. Their inner and external diameters are 2 and $6 \mu \mathrm{m}$, respectively, and slenderness ratio is large relatively. Moreover $\mathrm{ZnO}$ microcrystal tubes can be formed none but weight ratio of $\mathrm{Zn}$ powders to active carbon is $2: 1$.

As excitated at $380 \mathrm{~nm}$, the photoluminescence peaks of $\mathrm{ZnO}$ microcrystal tubes are peaks of a near UV band-edge emission ( $383 \mathrm{~nm}$ ) and a green emission at $500 \mathrm{~nm}$. But the intensity of green emission peak is far weaker than that of UV near band-edge emission peak, which indicats that the $\mathrm{ZnO}$ microcrystal tubes possess low defect density and fine quality.

\section{REFERENCES}

1. Iijima, S. Nature. 354, 5658, (1991).

2. Xia, Y.; Yang, P.; Sun, Y. et al. Adv. Mater. 15, 353, (2003).

3. Wan, Q.; Feng, P.; Wang, T. H. Chin. Micronanoelectron. Technol. 12, 1 , (2004).

4. Greene, L.; Law, M.; Goldberger, J. et al. Angew. Chem. Int. Ed. 42, 3031, (2003).

5. Mceuen, P. L. Phys. Word. 13, 31, (2000).

6. Lieber, C. M. Sci. Am. 285, 58, (2001).

7. Duan, X.; Huang, Y.; Cui, Y. et al. Nature. 409, 66, (2001)

8. Huang, M. H.; Mao, S.; Feick, H. et al. Science. 292, 1897, (2001)

9. Zhou, J.; Wang, Z. D.; Wang, L. et al. Superlattices Microstruct. 39, 314, (2006).

10. Kong, X. H.; Sun, X. M.; Li, X. L. et al. Mater. Chem. Phys. 82, 997, (2003).

11. Li, D. Z.; Sun, S. X., Zhang, W. M. et al. Chin. J. Inorg. Chem. 21, 1772, (2005).

12. Zhang, X. H.; Xie, S. Y.; Jiang, Z. Y. et al. J. Phys. Chem. B. 107, 10114, (2003).

13. Hu, J. Q.; Li, Q.; Meng, X. M. et al. Chem. Mater. 15, 305, (2003).

14. Xing, Y. J.; Xi, Z. H.; Xue, Z. Q. et al. Appl. Phys. Lett. 83, 1689, (2003).

15. Yang, L. P.; Li, Y.; Deng, H. Chin. J. Synth. Cryst. 35, 876, (2006).

16. Li, C. Q.; Fu, M. G. Chin. J. Inorg. Chem. 22, 1680, (2006).

17. Vanheusden, K.; Warren, W. L.; Seager, C. H. et al. J. App1. Phys. 79, 7983, (1996). 